\title{
Understanding the Perceptions of Omani Women Regarding Life After a Breast Cancer Diagnosis
}

$$
\text { فهم تصور المرأة العمانية عن الحياة بعد تشخيص سرطان الثدي }
$$

$$
\text { آسيا الريامي، ناديا نورعبد الهادي، محمد العزري }
$$

ABSTRACT: Objectives: There is a rising burden of breast cancer $(\mathrm{BC})$ in the Eastern Mediterranean Region (EMR), and its sociopsychological impact is a quickly growing health concern in this region. Because understanding cancer patients' perceptions of life is integral to their treatment, they are also a concern for healthcare providers. This qualitative study, therefore, explored changes in Omani women's perceptions of life after a BC diagnosis. Methods: Semi-structured interviews were conducted individually with 21 Omani women undergoing treatment for BC at the Oncology Ward of Muscat's Royal Hospital from March to May 2017. The collected data were subjected to qualitative content analysis. Results: After their cancer diagnosis, the women appeared to pass through three main stages in their coping processes. First, they passed through a stage of severe psychosocial distress and diminishment in personal identity. Next, they evolved strategies for coping based on cultural, religious and family resources. Finally, the women experienced acceptance and submission to the reality of the cancer as God's will with changes in attitudes and perceptions of the meaning of life. Conclusion: A BC diagnosis impacts Omani women severely, affecting their lives dramatically. They adopt coping strategies based on cultural, religious and spiritual beliefs. Healthcare providers need to acknowledge and facilitate women's spiritual and cultural coping strategies as an integral part of their treatment which holds potential to improve their prognosis. Such strategies should be individualised to suit each woman's experiences, perceptions and needs.

Keywords: Breast Neoplasm; Culture; Perceptions; Life; Women; Oman.

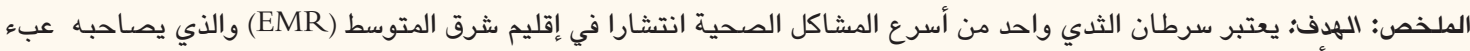

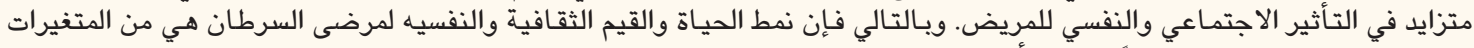

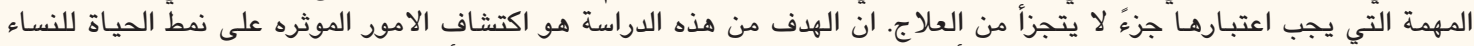

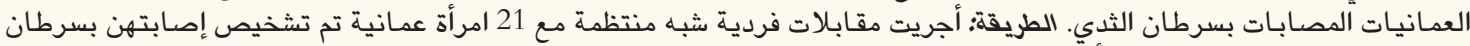

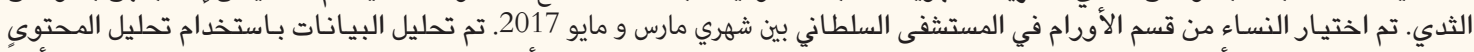

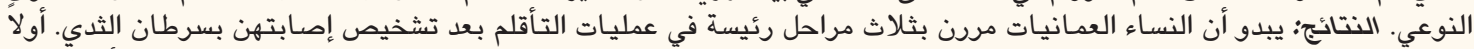

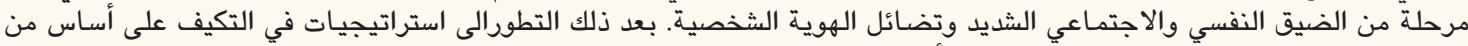

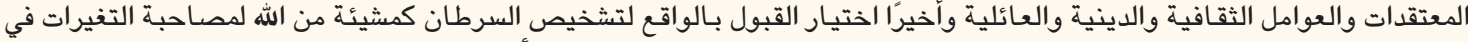

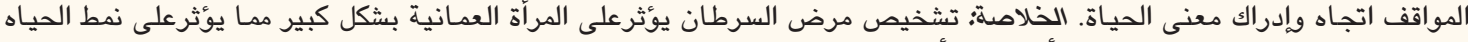

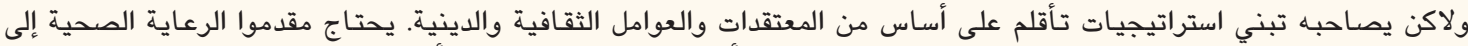

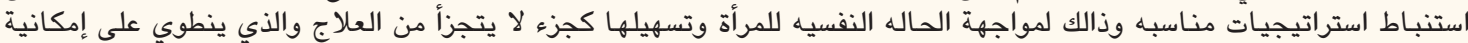
تحسين توقعات سيرالمرض. يجب أن تكون هذه الاستراتيجيات تتناسب مع تجارب كل امرأة على حده لتصوراتها لتهات واحتياجـاتها.

$$
\text { الكلمات المفتاحية: اورام الثدي؛ ثقافه؛ تصور؛ الحياة؛ النساء؛ عمان. }
$$

\section{Advances in KNOWLEDGE}

Breast cancer (BC) diagnosis and treatments have several negative consequences for Omani women's perceptions of life.

Omani women diagnosed with BC adopt several coping strategies to improve their perceptions of life. These strategies are constructed out of cultural, religious and spiritual beliefs.

The participating Omani women tended to seek more fundamental lifestyles to fulfil the essential needs of life per Maslow's hierarchy of needs.

\section{Application to Patient Care}

Healthcare providers caring for Omani women with BC should develop sensitivity towards the cultural, religious and spiritual factors that help these women cope with the disease.

Integrating women's personally evolved coping strategies into professional consultations on and management of their cases may also improve their satisfaction with care and adherence to treatment regimens. 
$\mathrm{B}$ REAST CANCER (BC) IS THE MOST COMMON cancer affecting women globally, with an estimated 2.1 million cases diagnosed each year. It represents $10 \%$ of all cancers diagnosed annually and approximately $15 \%$ of all cancer deaths among women. ${ }^{1}$ In the Eastern Mediterranean Region (EMR), BC is a leading cause of death and disability among women. ${ }^{2}$ Women in these countries usually present at later stages of the disease which leads to lower survival rates and negative impacts on their life perceptions compared to their counterparts in the developed world. ${ }^{3}$

Psychological symptoms of distress such as anxiety and depression are commonly found among BCaffected women in the EMR even years after diagnosis., ${ }^{4,5}$ These women are also at risk of developing a spectrum of psychological morbidities such as fatigue, negative thoughts, suicidal thoughts, fear of dying, a sense of loneliness and poor sexual and body images which all affect their perceptions of their own lives. ${ }^{5}$ These perceptions are further affected by challenges to their psychosocial and cultural belief systems, impacting their prognosis., ${ }^{4,5}$

Women's self-perceptions and their expectations about their futures as individuals and social beings undergo changes upon realisation that they have $\mathrm{BC}$. The complexity of the situation makes these changes difficult to define. In quantitative and mixed methods studies, the term quality of life (QOL) is often used to describe such self-perceptions. Because the current study followed a qualitative methodology, the authors framed the study not around a general investigation of QOL but instead on women's perceptions of their lives. $^{6}$

Emotional distress triggered by a $\mathrm{BC}$ diagnosis may have a profound psychosocial impact on BC survivors' life perceptions including their thoughts, emotions, attitudes and expectations; this distress is a predictor of treatment outcomes. ${ }^{7,8}$ There are psychological interventions, however, that have been found to help improve patients' perceptions of life and, consequently, their prognosis. ${ }^{9,10}$ Special attention needs to be given to patients whose perceptions of care priorities significantly differ from those of their caregivers. ${ }^{11}$ The few studies conducted in Arab countries on the impact of $\mathrm{BC}$ on patients' life perceptions endorse the importance of patients' functional abilities, spiritual beliefs, relationships with family and friends and the availability of medical and psychological care. ${ }^{12,13}$

Oman is an Arab country in the EMR, situated in the southeastern corner of the Arabian Peninsula. Out of an estimated country-wide population of 4.6 million, 2.5 million are Omani nationals. ${ }^{14}$ In this rapidly urbanising nation, about $21 \%$ of the total population reside in the national capital region, Muscat. $\mathrm{BC}$ accounts for $24.50 \%$ of all cancers affecting Omani women, and $12.79 \%$ of all malignancies in the Omani population. ${ }^{15}$ Most cases are diagnosed at younger ages (median: 49 years). Compared to Western women, however, Omani women tend to present for diagnosis later, leading to lower mean (63\%) five-year survival rates. ${ }^{15,16}$ Omani cancer patients from all parts of the country are referred for oncology treatment at the two major hospitals in Muscat: The Royal Hospital and the Sultan Qaboos University Hospital.

Previous studies on Omani women with BC showed that their main apprehensions centred on losing their femininity, cancer spreading to other parts of the body, the side effects of chemotherapy and genetic risks for their daughters., ${ }^{4,17}$ The strong BC stigma prevalent in Omani society causes some patients to believe they are being pitied by others, leading to social withdrawal. ${ }^{4}$ Despite such barriers, most Omani women diagnosed with $\mathrm{BC}$ are able to tap into traditional resources such as family support, religion and belief in God's will and power, which appears to guide them towards submission and acceptance of the reality of their cancer, with associated beneficial results on their lives.

This study sought to understand the perceptions of Omani women regarding their lives after $\mathrm{BC}$ diagnosis. For research that aims to understand people's lived experiences and their perceptions of those experiences, a qualitative approach is preferred..$^{18-20}$

\section{Methods}

Participants were recruited for this study between March and May 2017. The regional interview guide developed by the Reproductive Health Working Group (RHWG), a network of scholars from several Arab countries and Turkey, was adopted for this study. The RHWG guide uses concepts from medical, public health and social science to study women's health in its broader cultural context.. ${ }^{21}$ The areas of research interest were the emotional and cognitive experiences and perceptions of women diagnosed with $\mathrm{BC}$ and their impact on their lives. The RHWG topic guide was followed for collecting data because it is based on the combined expertise of several healthcare professionals and researchers who have brought their experiences and knowledge of $\mathrm{BC}$-affected women from different Arabic countries. ${ }^{21}$ The questions, which cover the impact of $\mathrm{BC}$ on each participant's perception of her life, include "How has your life been affected after diagnosis with breast cancer (work, household chores, leisure, etc.)" and "What were the reactions of your husband, family, friends to your disease and 
why? What were the strategies you used to cope with the diagnosis?" The present research team reviewed and modified the interview topics guide according to findings from pilot interviews conducted with five Omani women.

The purposive sampling strategy aimed for a maximum variation and was used to obtain a wider range of knowledge and lived experiences of women diagnosed at different cancer stages (i.e. local, metastasis) and on different cancer treatments (i.e. surgery, chemotherapy, radiotherapy, combined). ${ }^{22}$ All participants were from The Royal Hospital, Muscat, Oman, which treats the largest number of BC in-patients hailing from all parts of Oman. As generalisability is not an expected outcome of qualitative research, choosing patients from a single hospital was considered methodologically acceptable. ${ }^{18}$

Participants were recruited from the Oncology Ward over several visits. Semi-structured face-toface interviews were conducted individually with each woman, and each interview lasted 30-45 minutes. Before each ward visit, the head nurse briefed the second co-author on the medical and psychophysiological status of all participants to be visited that day. This procedure helped minimise intrusive queries to the patient. The second co-author accompanied by the Assistant Head Nurse visited the women daily for approximately two weeks. On a single day, only 3-4 women were interviewed to allow enough time for the interviews and to prevent daily repetition of the visit. Each interview lasted 45-60 minutes and was audio-recorded with patients' agreement and transcribed verbatim.

Qualitative content analysis is a widely used qualitative research technique and was applied inductively to analyse the data. ${ }^{20}$ The steps involved in inductive content analysis include open coding and creating categories and abstraction..$^{23}$ The transcripts were read several times by all three researchers to obtain a thorough sense of the entire text. The notes and headings were added to the text during reading, and the headings were transferred from the margins to coding sheets. The codes were then compared based on differences and similarities and sorted into categories and subcategories.

The abstraction involved formulating a general description where each category was named using content-characteristic words. The subcategories with similar events and incidents were also grouped together as categories and categories were then grouped as main categories. The proofs of abstraction were continued as far as was reasonably possible. ${ }^{23}$

A general definition of the main themes and subthemes were organised as appropriate. The first major theme was cancer diagnosis and impact on perception of life and subthemes were impact on personal identity and ability to discuss the illness. The second major theme was coping strategies and the subthemes were reliance on family support and submission to God's will. The third major theme was new perceptions of QOL.

The contents of the categories were discussed between all the authors. Disagreements were debated until consensus was reached. The data collection was stopped after 21 women when the saturation point in the analysis was achieved which was established as the point at which no new codes were occurring in the data and no new information could be elicited. ${ }^{20,23}$

This study was approved by the Research and Ethical Review and Approval Committee of the Ministry of Health of Oman (221/16). The purpose of the study was explained to the women individually. They were guaranteed confidentiality and anonymity of all collected data and assured that participation or non-participation would not affect the care they received. Written informed consent was obtained from the women who were recruited into the study.

\section{Results}

A total of 21 Omani women participated in this study. Their ages ranged from 25-63 (median: 42) years. Most participants were married $(n=18)$, urban residents $(n=12)$ and unemployed $(n=14)$ [Table 1 ]. The period since $\mathrm{BC}$ diagnosis ranged from two months to seven years with a median of 2.4 years. Ten participants were undergoing chemotherapy at the time of the interviews. The majority $(n=15)$ were unaware of the stage of their cancer at the time of the interviews, although most had been advised of their cancer's staging at the time of their diagnosis [Table 2].

The participants revealed experiencing different emotions including strong reactions when they were given their cancer diagnosis and also shared the impact of the disease on their personal priorities, spiritual life and perceptions of family structure and support. From analysis, three themes emerged-the emotional trauma of cancer diagnosis, the evolution of coping strategies and changes in their perceptions of life. These stages are subsequently discussed and are illustrated by representative quotations from the transcribed text. ${ }^{20,23}$

The $\mathrm{BC}$ diagnosis was shocking for the women and created much anxiety. The participants also felt exhausted due to the side effect of chemotherapy, which affected their daily normal activities. A minority of participants, however, revealed that they did not feel much anxiety around a possible BC diagnosis as 
Table 1: Participants' socio-demographic characteristics of Omani women attending at the Oncology Ward of The Royal Hospital, Muscat, Oman $(\mathrm{N}=21)$

\begin{tabular}{lc} 
Characteristic & $\mathbf{n}(\%)$ \\
Age at time of diagnosis in years & \\
$25-35$ & $4(19.0)$ \\
$36-45$ & $10(47.6)$ \\
$46-55$ & $5(23.8)$ \\
$56-65$ & $2(9.50)$ \\
Age range in years & $25-63$ \\
Median age in years & 42 \\
Marital status & \\
Single & $1(4.7)$ \\
Married & $18(85.7)$ \\
Divorced & $1(4.7)$ \\
Widow & $1(4.7)$ \\
Educational level & \\
No formal education & $8(38.1)$ \\
Primary education & $4(19.0)$ \\
Secondary school education & $5(23.8)$ \\
College/above & $4(19.0)$ \\
Residential locality & \\
Urban & $12(57.1)$ \\
Rural & $9(42.8)$ \\
Employment status & \\
Employed & \\
Unemployed & $(33.3)$ \\
\hline
\end{tabular}

they had expected it due to a history of cancer in their families:

"Of course I am shocked till now. I faced huge panic during the previous period and I feel weak now with the chemotherapy, all my life changed. Earlier, I had only migraines and my life was better" (woman 18).

"I feel tired and cannot even go to the supermarket, but Allah will give me back good things if I accept my fate" (woman 12).

"I expected to have cancer; my mother died with cancer and my sister has leukaemia, I was a bit cool while waiting for the result" (woman 5).

Some women felt that the suffering of $\mathrm{BC}$ was enormous compared to their previous illnesses:

"Now I realized that all the previous illnesses I got and went several times to the hospital were trivial, were nothing, now only I am really and seriously ill" (woman 17).

"Before, when someone said take care of yourself
Table 2: Clinical data as perceived by of Omani women attending at the Oncology Ward of The Royal Hospital, Muscat, Oman $(\mathrm{N}=21)$

\begin{tabular}{|c|c|}
\hline Condition & n (\%) \\
\hline \multicolumn{2}{|l|}{ Disease stage at the time of diagnosis* } \\
\hline Local & $3(14.3)$ \\
\hline Metastasis & $0(0)$ \\
\hline Does not know & $7(33.3$ \\
\hline Stage 1 & $2(9.5)$ \\
\hline Stage 2 & 4. (19.0) \\
\hline Stage 3 & $3(14.3)$ \\
\hline Stage 4 & $2(9.5)$ \\
\hline \multicolumn{2}{|l|}{ Cancer stage at the time of interviews } \\
\hline Local & $1(4.7)$ \\
\hline Metastasis & $3(14.3)$ \\
\hline Does not know & $15(71.4)$ \\
\hline Stage 1 & $0(0)$ \\
\hline Stage 2 & $1(4.7)$ \\
\hline Stage 3 & $1(4.7)$ \\
\hline Stage 4 & $0(0)$ \\
\hline \multicolumn{2}{|l|}{ Disease duration } \\
\hline Mean duration & 2.4 years \\
\hline Range of duration & 2 months -7 years \\
\hline \multicolumn{2}{|c|}{ Perception of initial management (previous) } \\
\hline Total mastectomy only & $3(14.3)$ \\
\hline Partial mastectomy only & $1(4.7)$ \\
\hline Chemotherapy only & $5(23.8)$ \\
\hline Radiotherapy only & $0(0)$ \\
\hline Surgery with chemotherapy & $4(19.0)$ \\
\hline $\begin{array}{l}\text { Surgery with chemotherapy and } \\
\text { radiotherapy }\end{array}$ & $8(38.1)$ \\
\hline \multicolumn{2}{|c|}{ Perception of medical management (current) } \\
\hline Surgery only & $0(0)$ \\
\hline Chemotherapy & $10(47.6)$ \\
\hline Radiotherapy & $1(4.7)$ \\
\hline Chemotherapy and radiotherapy & $0(0)$ \\
\hline Surgery with chemotherapy & $1(4.7)$ \\
\hline $\begin{array}{l}\text { Surgery with chemotherapy and } \\
\text { radiotherapy }\end{array}$ & $0(0)$ \\
\hline $\begin{array}{l}\text { Supplementary medicines (e.g. } \\
\text { hormonal, adjuvant therapy, Zometa, } \\
\text { etc.) }\end{array}$ & $8(38.1)$ \\
\hline Does not know & $1(4.7)$ \\
\hline
\end{tabular}


or your health, I was considering as casual and unintended words, just words, but now I realize how valuable it was" (woman 13).

Women developed a perception of bodily disfigurement and physical appearance due to the potentially devastating consequences of treatment side-effects including alopaecia and mutilation. These physical changes can cause dissatisfaction with appearance, perceived loss of femininity and body integrity and a decreased feeling of physical attractiveness, thus impacting sexual lives. As a result, the women expressed feelings of nervousness and being out of harmony with their husbands and families:

"The worse thing is that I felt I was an incomplete woman, no breast and no hair" (woman 3).

"I was nervous and badly upset, I stopped caring about my husband or my sexual life and did not feel in love with him, one breast was removed, the hair has fallen. I am now half a woman" (woman 2).

The women struggled with their identity as mothers and described themselves as falling short of being good mothers. Some of them expressed anxieties and concerns over their unfulfilled obligations toward their children in case of their early death and feared that their children would become half-orphans:

"I am thinking of my children, what would happen to them if I died?" (woman 15).

"Now I am thinking about my loans, I panic about not settling them if anything happened to me. I was not thinking of that before the illness" (woman 8).

Women reported being insecure talking about their breast cancer with families or friends either to protect them from the impact of their diagnosis or might be because of the concern of being stigmatised. Only a few felt like discussing this after starting treatment but they refrained from giving details:

"I absolutely do not want to talk about this (breast cancer diagnosis)" (woman 20).

"I can talk with my family (of breast cancer) but not in detail" (woman 10).

The women now wished to live in peace with their relatives. Family relationships previously taken for granted had now become important. They also felt closer to their in-laws and friends whose emotional support made them feel happy. Some women felt that their relationships with their husband, family and friends improved after diagnosis. They perceived that they were receiving more emotional and moral support than prior to diagnosis:

"I felt closer to my husband, my family and friends after I got the cancer. We were not really close to each other before the illness" (woman 1).

"Now I have no problems with my husband's family unlike before, now they are treating me better and showing a lot of sympathy, that was not the case at all before my illness as there were a lot of conflicts and aggressiveness in our relations" (woman 12).

Women expressed the belief that all illnesses, including cancer, come from Allah (God). They expressed their deep wish to be more religious and closer to God than ever before through prayer and recitation of The Holy Quran. Despite the physical side effects of chemotherapy, they said they strove to submit to God's will and, through acceptance of their divinely determined destiny, seek His support and approval. This relationship, they said, provided them with the strength to face afflictions. They also felt that their failing Allah's test might otherwise lead to more disasters and divine retributions:

"What happened has happened, what is the use of crying and making noise (dhajah)? ...yes I was sad at the beginning, but now I feel better because I accepted my fate and left everything to Allah, this made me strong, and less anxious, praise be to Allah" (woman 6).

"I accepted what Allah wrote for me; I believe it is for good reasons, thanks to Allah" (woman 14).

"Yes, they removed a part of my body but this illness is from Allah. Should I be angry or fight with Allah?" (woman 21).

The women's perception of what constituted a desirable life was fundamentally altered by their illness. Prior to their diagnosis, they said, they sought wealth and social status. Now such erstwhile benchmarks of QOL were perceived as trivial. Currently, they seemed to equate QOL with more fundamental necessities such as physical health, family support and satisfaction of basic life requirements:

"Quality of life (now) means good health, good family relations and peace, all this changed after my illness, I am unhappy..." (woman 5).

"I made a huge effort and collected money to have a beautiful villa and that was my main dream, but I see my dream now as very trivial, good health is a major issue now..." (woman 3).

"Now only after getting cancer I realised that money or wealth are nothing, they are not valuable if you have cancer, I only want now to recover and get my good health back. Quality of life means good health" (woman 21).

"Imagine how life looks like with illness like cancer?" (woman 8).

"It is almost the same, because if you accept what is written to you by God, it means you will live your life in a good way, you will be satisfied and you will feel happy" (woman 3).

"Quality of life and satisfaction with life are the same, yes, the same" (woman 5).

Women now wished to accept their life and fate 
with self-esteem irrespective of their standard of living. The general attitude seemed to be moving towards finding satisfaction and meaning in the present life and abandoning desires for social prestige and luxuries:

"It is acceptance; it is important to accept all the afflictions to be able to survive" (woman 5).

"Yes, we have to accept, it is not possible to fight the fate" (woman 11).

"Now, I do not look for luxury or anything. It is only health, it is the main component of quality and also satisfaction with life, how can you do anything or achieve anything if you are not in good health" (woman 13).

\section{Discussion}

To the researchers' knowledge, this qualitative study is the first conducted in Oman to understand the effect of a $\mathrm{BC}$ diagnosis on the life perceptions of Omani women. The participants indicated that BC diagnosis was a life-changing event, and the women were left emotionally traumatised with compromised identities. The participants described anticipating more trauma and losses, refusing to discuss their illness with others and, for some, becoming socially reclusive. To cope with the emotional and physical trauma of cancer, they sought out strategies based on cultural values and religious beliefs. These strategies included increased religiosity and submission to God's will, acceptance of the inevitability of the disease and a strong shift in perceptions of life towards satisfying the basic needs such as health and family togetherness. ${ }^{5}$ This finding is congruent with those of other studies, confirming that women diagnosed with $\mathrm{BC}$ usually experience a precipitous change in their lives, and psychological symptoms begin emerging even as they await diagnostic results; however, they adopt various strategies to cope with their distress. ${ }^{4,5,24}$

The participants revealed that their family relations, earlier taken for granted, had now become warm and vital. Here they may have been supported by Omani tradition which is collective in nature and puts great value on sharing aspects of life between relatives and neighbours. Studies suggest that social and familial support render symptoms more bearable and help enhance the life perceptions of BC-affected women. ${ }^{5,25}$

Participants' religious convictions were found to be strong and homogeneous. They expressed the conviction that cancer was a test from God and expressed a wish to submit to divine will by becoming more religious. While Islam considers physical and mental well-being as measures of good health, it also teaches that everything is determined by the sovereign will of God who is the source of all health and illness. ${ }^{26}$ The task of the devotee is to fully submit to God's will. The impact of Islamic submission to divine will on women's lives was studied among a cohort of BC patients in Singapore where several women reported spiritual experiences with attendant enhancements of their life. ${ }^{27}$ While the current participants did not report spiritual experiences as part of their devotional activities, the potential of such experiences for enhancing life perceptions among cancer patients is increasingly gaining researcher attention. ${ }^{28}$

Previous research with cancer patients who engage in Buddhist mindfulness meditation (a secular meditation which seeks to observe and accept the reality of the present moment) found spiritual experiences leading to sustained enhancement of patients' experience of life. ${ }^{29}$ Neuroscientific investigations also endorse the possibility that spiritual practices geared towards submission and acceptance of reality may improve cancer patients' life perceptions. ${ }^{30}$ Such findings emphasise the need for all caregivers to acknowledge the life-enhancing benefits of submission/acceptance-oriented spiritual practices for $\mathrm{BC}$ patients and facilitate these to the highest extent possible.

Another significant takeaway from the current study is the emphatic manner in which the participants declared that their perceptions of life had changed drastically in the process of dealing with the reality of $\mathrm{BC}$. Living with $\mathrm{BC}$ caused them to dismiss their former aspirations to wealth and social status as trivial and gravitate towards more basic needs such as physical health, family support and submitting to divine will. This dramatic shift can be explained by Maslow's hierarchy of needs where the basic onesphysical survival, personal safety, sense of belonging and being loved-need to be satisfied before secondary needs such as ego, esteem and self-actualisation can be contemplated. ${ }^{31,32}$

It could be hypothesised that such a step-down in the hierarchy of needs leaves the mind relatively free for engaging in religious practices based on submission and acceptance and paves the way to spiritual transcendence as manifested in studies elsewhere. ${ }^{31}$ Healthcare providers need to be aware that such downward shifts in the need-hierarchy among $\mathrm{BC}$ patients is a natural and possibly beneficial coping mechanism which supports patients through transitions.

It is essential to establish trustworthiness of findings in qualitative research. A reasonable degree of credibility was achieved by the way the interviews were conducted including the questions asked. The 
researchers independently reviewed the transcripts during regular team meetings and explored the patients' underlying reasoning. ${ }^{19,23}$ Despite this approach, the study has certain limitations. The interview transcripts showed significant conformity in the participant responses which is a characteristic of collective cultures which seek social unity. The findings may not be applicable to women living under more individualistic cultural norms such as in the West. ${ }^{33}$ Indeed, this study was not designed to filter out cultural characteristics. Finally, this study's methodology would have been stronger if triangulation was incorporated through, for example, interviewing patients' family members and healthcare providers whose influences are critical in the lives of Omani women diagnosed with BC.

\section{Conclusion}

This qualitative study reveals that Omani women felt emotionally devastated by $\mathrm{BC}$ diagnoses. Using traditional support systems from culture, family and religion, women were able to reorient themselves by anchoring to fundamental values and accepting the reality of their illness as part of a divine plan. The findings underscore the need of healthcare providers to be aware of the experiences, perceptions and coping strategies of Omani women with BC. Healthcare providers should regard their patients' lives, actively understand them and incorporate familiarisation strategies as much as possible into overall treatment plans.

These findings are likely to be relevant to other Arab Islamic countries with socio-demographic and cultural characteristics similar to those of Oman. Healthcare providers who work with women with BC in such countries should be aware of the importance of culturally determined factors such as social cohesion, religion and spirituality in achieving better QOL. These needs imply highly individualised care which requires caregivers to be cognisant of cultural values and beliefs, individual understanding of the illness and patients' knowledge of and expectations around treatment. Caregivers need to respect and facilitate patients' spiritual practices, particularly those geared towards submission and acceptance of diagnoses, as these are known to enhance the lives of women with BC.

While paying attention to women's expectations, feelings and needs, it is essential that a caregiver's own beliefs and value systems are not imposed on patients. A team approach may be preferable and should be one that includes the treating doctor, trained nurses, psychiatrists, health educators, dieticians and close family members.

\section{CONFLICT OF INTEREST}

The authors declare no conflict of interest.

\section{FUNDING}

No funding was received for this study.

\section{ACKNOWLEDGEMENTS}

The authors thank the members of RHWG as well as all the participating women and the staff working in the Women's Oncology Ward of The Royal Hospital for their cooperation.

\section{References}

1. World Health Organization (WHO). Cancer-Breast cancer. Secondary cancer-Breast cancer 2019. From: www.who.int/ cancer/prevention/diagnosis-screening/breast-ancer/en/ Accessed: Mar 2020.

2. World Health Organization. Guidelines for the early detection and screening of breast cancer. From: apps.who.int/iris/ handle/10665/119811 Accessed: Mar 2020.

3. Elobaid Y, Aw TC, Lim JNW, Hamid S, Grivna M. Breast cancer presentation delays among Arab and national women in the UAE: A qualitative study. SSM Popul Health 2016; 2:155-63. https://doi.org/10.1016/j.ssmph.2016.02.007.

4. Al-Azri M, Al-Awisi H, Al-Rasbi S, El-Shafie K, Al-Hinai M, Al-Habsi $\mathrm{H}$, et al. Psychosocial impact of breast cancer diagnosis among Omani women. Oman Med J 2014; 29:437-44. https:// doi.org/10.5001/omj.2014.115.

5. Al-Azri M, Al-Awisi H, Al-Moundhri M. Coping with a diagnosis of breast cancer-literature review and implications for developing countries. Breast J 2009; 15:615-22. https://doi. org/10.1111/j.1524-4741.2009.00812.x.

6. National Wellness Institute of Australia (NWIA). Definitions of wellbeing, quality of life and wellness. From: www.scribd.com/ document/131650029/Definitions-of-Wellbeing-Quality-ofLife-and-Wellness Accessed: Mar 2020.

7. Conley C, Bishop B, Andersen B. Emotions and emotion regulation in breast cancer survivorship. Healthcare 2016; 4:56. https://doi.org/10.3390/healthcare4030056.

8. Haddou Rahou B, El Rhazi K, Ouasmani F, Nejjari C, Bekkali R, Montazeri A, et al. Quality of life in Arab women with breast cancer: A review of the literature. Health Qual Life Outcomes 2016; 14:64. https://doi.org/10.1186/s12955-016-0468-9.

9. Hunter MS, Coventry S, Hamed H, Fentiman I, Grunfeld EA. Evaluation of a group cognitive behavioural intervention for women suffering from menopausal symptoms following breast cancer treatment. Psychooncology 2009; 18:560-3. https://doi. org/10.1002/pon.1414.

10. World Health Organization. Cancer prevention and control in the context of an integrated approach. From: apps.who.int/gb/ ebwha/pdf_files/EB140/B140_31-en.pdf Accessed: Mar 2020.

11. Meropol NJ, Egleston BL, Buzaglo JS, Benson AB 3rd, Cegala DJ, Diefenbach MA, et al. Cancer patient preferences for quality and length of life. Cancer 2008; 113:3459-66.

12. Alawadi SA, Ohaeri JU. Health-related quality of life of Kuwaiti women with breast cancer: A comparative study using the EORTC Quality of Life Questionnaire. BMC Cancer 2009; 9:222. https://doi.org/10.1186/1471-2407-9-222. 
13. Huijer HA-S, Abboud S. Health-related quality of life among breast cancer patients in Lebanon. Eur J Oncol Nurs 2012; 16:491-7. https://doi.org/10.1016/j.ejon.2011.11.003.

14. National Center for Statistics and Information. Population clock. From: www.ncsi.gov.om/Pages/NCSI.aspx Accessed: Mar 2020.

15. Al-Lawati NA, Al-Bahrani BJ, Al-Raisi SS, Al-Lawati JA. Twenty-year trends of cancer incidence in Omanis, 1996-2015. Oman Med J 2019; 34:361-87.

16. Al-Lawati JA, Al-Zakwani I, Fadhil I, Al-Bahrani BJ. Cancer Incidence in Oman (1996-2015). Oman Med J 2019; 34:271-3. https://doi.org/10.5001/omj.2019.55.

17. Al-Azri MH, Al-Awisi H, Al-Rasbi S, Al-Moundhri M. Coping with a diagnosis of breast cancer among Omani women. J Health Psychol 2014; 19:836-46. https://doi.org/10.1177/13 59105313479813.

18. Leung L. Validity, reliability, and generalizability in qualitative research. J Family Med Prim Care 2015; 4:324-7. https://doi. org/10.4103/2249-4863.161306.

19. Hammarberg K, Kirkman M, de Lacey S. Qualitative research methods: When to use them and how to judge them. Hum Reprod 2016; 31:498-501. https://doi.org/10.1093/humrep/dev334.

20. Patton MQ. Qualitative evaluation and research methods. SAGE Publications, 1990.

21. DeJong J, Zurayk H, Myntti C, Tekçe B, Giacaman R, Bashour H, et al. Health research in a turbulent region: The Reproductive Health Working Group. Reprod Health Matt 2017; S1:4-15. https://doi.org/10.1080/09688080.2017.1379864.

22. Palinkas LA, Horwitz SM, Green CA, Wisdom JP, Duan N, Hoagwood K. Purposeful sampling for qualitative data collection and analysis in mixed method implementation research. Adm Policy Ment Health 2015; 42:533-44. https:// doi.org/10.1007/s10488-013-0528-y.

23. Elo S, Kyngäs $H$. The qualitative content analysis process. J Adv Nurs 2008; 62:107-15. https://doi.org/10.1111/j.1365-2648.200 7.04569.x.5.
24. Montazeri A. Health-related quality of life in breast cancer patients: A bibliographic review of the literature from 1974 to 2007. J Exp Clin Cancer Res 2008; 27:32. https://doi. org/10.1186/1756-9966-27-32.

25. Attum B, Waheed A, Shamoon Z. Cultural competence in the care of Muslim patients and their families. Treasure Island: StatPearls Publishing, 2019.

26. Sabry WM, Vohra A. Role of Islam in the management of Psychiatric disorders. Indian J Psychiatry 2013; 55:S205-14. https://doi.org/10.4103/0019-5545.105534.

27. Devi M, Fong K. Spiritual experiences of women with breast cancer in Singapore: A qualitative study. Asia Pac J Oncol Nurs 2019; 6:145. https://doi.org/10.4103/apjon.apjon_77_18.

28. Rudaz M, Ledermann T, Grzywacz J. The influence of daily spiritual experiences and gender on subjective well-being over time in cancer survivors. Arch Psychol Religion 2019; 41:159-71. https://doi.org/10.1177/0084672419839800.

29. Masel E, Schur S, Watzke H. Life is uncertain. Death is certain. Buddhism and palliative care. J Pain Symptom Manage 2012; 44:307-12.https://doi.org/10.1016/j.jpainsymman.2012.02.018.

30. Salsman JM, Fitchett G, Merluzzi TV, Sherman AC, Park CL. Religion, spirituality, and health outcomes in cancer: A case for a meta-analytic investigation. Cancer 2015; 121:3754-9. https://doi.org/10.1002/cncr.29349.

31. Koltko-Rivera M. Rediscovering the later version of Maslow's Hierarchy of Needs: Self-transcendence and opportunities for theory, research, and unification. Rev Gen Psychol 2006; 10:302-17. https://doi.org/10.1037/1089-2680.10.4.302

32. Mawardika T, Afiyanti Y, Rahmah H. Gynecological cancer inpatients need more supportive nursing care than outpatients: A comparative study. BMC Nurs 2019; 18. https://doi. org/10.1186/s12912-019-0355-x.

33. Al-Adawi S, Al-Zakwani I, Obeid Y, Zaidan Z. Neurocognitive functioning in women presenting with undifferentiated somatoform disorders in Oman. Psychiatry Clin Neurosci 2010; 64:555-64. https://doi.org/10.1111/j.1440-1819.2010.02117.x. 